\title{
Mulheres de Satã: uma leitura historiográfica sobre sexualidade e inquisição
}

\author{
Ana Luiza de Oliveira e Silva \\ "We are the servants of God, \\ We believe in the Devil \\ And we've found his mark on you, \\ Confess witch,"*
}

Situando o presente ensaio, teremo-lo girando em torno do seguinte tema: feitiçaria na época moderna, mais especificamente séculos XV e XVI. Neste contexto, será abordado como eixo principal a questão de por que eram mulheres as mais propícias a serem consideradas e, consequentemente, condenadas pela prática da bruxaria ${ }^{2}$. Serão feitas analogias ao comportamento das pessoas da época tratada, sua religiosidade e, principalmente, seu imaginário, entrando, portanto, na imagem do Diabo. A partir de questões levantadas sobre suas tentações e conquistas, serão englobados, aí, assuntos como sexualidade e morte. Heresias, feitiços e sabás também terão lugar no presente artigo, além de abordagens sobre comportamento e cultura da época. Porém, a linha dirigente será a sexualidade, ou melhor, o caráter sexual existente nas acusações de feiticeiras. Contrapondo diferentes autores, tentaremos entender por quais vias o corpo feminino se tornou um chamariz para a questão do sobrenatural.

Permeando o imaginário da época citada, a figura do Diabo mostra-se como um dos pontos mais fortes. Keith Thomas, citado por Delumeau, dirá que a Reforma protestante na Europa, na medida em que rejeitava imagens e rituais católicos, foi a causa de um aumento na crença dos poderes do Demônio.

Neste contexto, onde sua imagem possuía tamanha importância e tanto

Trecho retirado da música The trial (Chambre Ardente), da banda King Diamond. The eye. EUA: Roadracer Records, 1990

${ }^{2}$ Vale lembrar aqui a existência de uma diferença, citada por alguns autores e pela antropologia, entre a feitiçaria e a bruxaria. A primeira é tida como um conjunto de 'práticas mágicas', como a produção de filtros, poçổes ou amuletos usados com o objetivo de produzir efeitos em pessoas ou ainda, alterar o curso natural das coisas. Já a chamada bruxaria é definida como sendo um 'dom natural' existente na própria pessoa, ou seja, os efeitos causados por esta prática estão no âmbito de técnicas mentais exercidas pela 'bruxa' com um propósito previamente definido. Porém, a separaçâo de tais categorias não fará parte do presente trabalho, visto que, durante os processos conduzidos pela Inquisição, essa distinção não possuía grande influência. Entretanto, o ato de levar a efeito tais poderes sobrenaturais, chamado como fosse, teve, principalmente durante os séculos XV e XVI, uma enorme repercussão na vida de pessoas isoladas, mas não só, de todo um conjunto de culturas e mentalidades. 
poder the era conferido, ao ponto de ser dito que "o Diabo (...) não é capaz de interferir nas ações naturais - tais como no comer, no caminhar, no ficar de pé - porque, se o fosse, destruiria todo o mundo"3, seus agentes também passaram a ter destaque especial. A idéia da existência de relações travadas entre feiticeiros e o Senhor das Trevas certamente marcou o universo místico popular europeu, já que, "uma vez aceita a possibilidade de sua aparição pessoal neste mundo, estava-se a um passo da noção de que havia indivíduos que celebravam com ele uma espécie de contrato semifeudal." 4 .

Neste contexto, as bruxas tomaram a dianteira em tal estigma. Julio Baroja diz que, provavelmente, cultos a divindades locais ou regionais passaram, aos poucos, sendo deturpadas para a imagem de adoração ao Demônio cristão. De qualquer forma, as bruxas, por estarem diretamente ligadas ao Diabo, tinham suas atitudes julgadas como sendo maléficas. O Malleus Maleficarum - principal livro sobre bruxaria e sua relação direta com o sexo feminino, um verdadeiro manual publicado em 1486 por Heinrich Kramer e James Sprenger - contém diversos exemplos de como tais pessoas eram portadoras de desgraças, ou seja, seus poderes eram confirmados na medida em que podiam adoecer o gado, destruir construções e matar pessoas com raios ou ainda, destruir plantações com chuvas de granizo. Neste ponto, vale chamar a atenção para o fato de que as desgraças naturais não mais eram atribuídas a Deus, como forma de castigo - como ditava o pensamento medieval, principalmente em meados do ano 1000 - mas sim a pessoas, o que denota uma individualização, ou seja, um aumento na importância concedida ao indivíduo, durante a Idade Moderna. Paralelamente a estes medos, havia o receio de que as seitas de bruxas pudessem destruir as estruturas sociais, culturais e religiosas então vigentes. Na medida em que havia a "convergência da religião ortodoxa e da religião demoníaca sobre um mesmo plano de religiosidade elementar", a feitiçaria, ou ainda, sua perseguição, devem ser relacionadas "a uma religião e uma cultura que se sentiram ameaçadas"6. Apesar da pouca probabilidade destes receios se concretizarem, o medo coletivo contribuiu para a superestimação do poder das bruxas.

Ora, por ser verificada uma estreita relação entre essas feiticeiras vistas como praticantes de malefícios - e Satã, a prática de feitiçaria foi "doravante assimilada a uma heresia"7. Em contrapartida, Keith Thomas irá contradizer isto, afirmando que o crime da bruxaria era, por muitas vezes, ou

\footnotetext{
${ }^{3}$ KRAMER e SPRENGER. Malleus Maleficarum, [1486]. Rio de Janeiro: Rosa dos Tempos, 2000, p. 135

${ }^{4}$ THOMAS, Keith. Religião e o declínio da magia ${ }_{2}$ São Paulo: Cia das Letras, 1991, p. 384

${ }^{5}$ GINZBURG, Carl. Mitos, emblemas e sinais. São Paulo, Cia das Letras, 1989, p. 33

${ }^{6}$ DELUMEAU, Jean. História do medo no ocidente. São Paulo: Cia das Letras, 2001, p. 350

${ }^{7}$ Idem, p. 352
} 
pelo menos na Inglaterra, visto menos como heresia e mais como crime antisocial.

A "bruxaria (venefica) ou magia maléfica, que se utiliza farta de encantações e invocações de espíritos impuros" ${ }^{\text {, }}$, foi perseguida, ou ainda, controlada pelos Tribunais da Inquisição, dos quais falaremos mais adiante. Neste contexto, havia certos indivíduos mais propícios à inclusão em acusações de natureza maligna - entenda-se aqui, os de âmbito sobrenatural. Esses "mágicos heretizantes, necromantes ou invocadores do Diabo" eram, em sua maioria, pessoas pobres, isoladas do convívio social, por algum motivo reclusas, ou ainda, excêntricas. Delumeau irá frisar um aspecto importante a ser observado: "sem dúvida, é fácil atribuir culpa a um mais pobre, cujas possibilidades de defesa são reduzidas." suspeita de feitiçaria pode levar a verdadeiras formas de isolamento social, (...) por outro lado, as singularidades de hábitos e comportamentos atraem facilmente primeiro a suspeita, depois a acusação de feitiçaria." "1 Para a mentalidade das pessoas da época, tonava-se óbvio o fato de que "os bruxos e as feiticeiras situavam-se nas margens da comunidade; e sua conspiração era inspirada num inimigo externo - o inimigo por excelência, o Diabo." 12

Este preconceito, se pode ser assim chamado em relação a pessoas isoladas, recaía definitivamente com mais peso sobre as mulheres. "A maioria dos acusados vivia em um estado de impotência e desespero" 13 , fosse por sua extrema pobreza, sua falta de uma família ou aliados, ou até por um 'desespero religioso'. Portanto, em alguns casos "a fama de bruxa, para uma velha [por exemplo], podia ser a última linha de defesa, garantindo-lhe um tratamento decente por parte das pessoas de sua aldeia." 14 Julio Baroja vem ainda com outras noções sobre a criação da identidade de bruxa, como por exemplo a que elas criariam a imagem de Satã e os vôos em vassouras ao fazer uso de plantas estupefacientes. Eram estas, por conseguinte, as linhas que permeavam o início da construção da figura de uma bruxa.

Contudo, este quadro tem outros desmembrantes. A autora Anne Barstow nos emprestará um caso por ela estudado que servirá como primeiro exemplo de acusação de feitiçaria a mulheres: “...era uma mulher sozinha havia muito tempo, portanto suspeita de seu comportamento sexual, era pobre e viúva, portanto não tinha um homem para defendê-la." ${ }^{15}$ Já que a conduta da

\footnotetext{
${ }^{8}$ EYMERICH, Nicolau. Directorium Inquisitorium, Brasília: Rosa dos Tempos, 1993, p. 134

${ }^{9}$ EYMERICH, Op. Cit., p. 133

${ }^{10}$ DELUMEAU, Op. Cit., p. 378

${ }^{11}$ GINZBURG, Carl. Mitos, emblemas e sinais, São Paulo: Cia das Letras, 1989, p. 22

12

13 THOMAS, Keith. Op. Cit., p. 420 História noturna. São Paulo: Cia das Letras, 1991, p. 79

${ }^{14}$ Idem, p. 455

${ }^{15}$ BARSTOW, Anne L. Chacina de feiticeiras, Rio de Janeiro: José Olympio, 1995, p. 37
} 
mulher, ou ainda, sua situação, era um tanto misteriosa aos olhos do resto da comunidade, o imaginário popular passou a se curvar exatamente sobre esse time de mulheres 'desamparadas'. "O Diabo podia seduzir uma mulher, colocando-a a seu serviço, quando ela ficava sexualmente excitada ou melancólica"16. Pela inexistência de um marido ou companheiros - entenda-se amigos ou familiares - essas mulheres estavam sujeitas a tal sedução demoníaca. Portanto, "o papel do Diabo tornou-se uma preocupação comum (...) na medida em que colocava sentido ao comportamento delas". ${ }^{17}$

Muitos acreditavam que certas mulheres "envolver-se-iam com a bruxaria como conseqüência de não serem permitidas de casar e de se tornarem mães". ${ }^{18}$ Neste contexto, a maternidade também passava a possuir um caráter um tanto 'místico'. Por sua proximidade com tal atividade, outras mulheres que não necessariamente eram isoladas da comunidade - passaram a se tornar alvo de suspeitas e acusações: as parteiras. O Malleus partirá do princípio da existência de "bruxas parteiras que primeiro as matam [crianças recémnascidas] e depois as oferecem, em blasfemo rito, aos demônios" "19, além de citar inclusive mães que oferecem seus próprios filhos ao Diabo. "O medo dos poderes mágicos das parteiras e das curandeiras das aldeias provocou a demonização das habilidades curativas das mulheres" ${ }^{20}$, ou seja, todo um conjunto de 'sabedorias populares' foi posto sob suspeita, porque além da -habilidade de proporcionar partos e abortos, davam conselhos para o amor, faziam predições que por acaso se realizavam e tinham conhecimento sobre plantas para o uso medicinal. Pelo fato de tais atividades e/ou saberes estarem infinitamente mais ligados ao sexo feminino, essas 'mulheres sábias' passaram a ser estigmatizadas como bruxas, pois "possuíam o poder de curar, um poder que todos acreditavam ser também o de matar"21. Outro indício da ligação entre a bruxaria e as mulheres, ou melhor, a aspectos femininos era a crença em que "usualmente sua [da bruxa] magia era direcionada contra a fertilidade (...), bruxas não conseguiam chorar e velhas viúvas não conseguiam nem menstruar, nem amamentar crianças". ${ }^{22}$

Já Delumeau tratará este assunto fazendo, primeiramente, um contraponto com questões, de natureza social e econômica. Em um contexto de grande pobreza, o ato de pedir esmolas tornava-se comum e uma conseqüente negação deste pedido causava imenso medo de que aquele mendicante pudesse vir a vingar-se. Outra questão é relativa à Reforma protestante, visto que, a

\footnotetext{
${ }^{16}$ Idem. p. 162

${ }^{17}$ ROPER, Lyndal. Oedipus \& the Devil. Londres: Routledge, 1994, p. 231

${ }^{18}$ Idem, p. 215

${ }^{19}$ KRAMER e SPRENGER. Op. Cit., p. 283

${ }^{20}$ BARSTOW, Op. Cit., p. 132

${ }^{21}$ Idem, p. 37

${ }^{22}$ ROPER, Op. Cit., p. 208
} 
partir do momento em que, como já foi citado, passa-se a negar os ritos católicos, ou melhor, certas formas de 'magia cristianizada', aqueles que por vez continuassem a exercê-los correriam risco de uma acusação. Como "o elemento feminino é por excelência aquele que permanece ligado às tradições" 23 , explica o autor, provavelmente seria este mais um dos motivos pelo qual era sobre as mulheres que mais pairavam as suspeitas. Se, por diversas vezes, referimo-nos às mulheres ou às bruxas, deve-se entender a bruxaria não como um fato isolado, individual, mas sim como um fenômeno coletivo, ou seja, não era apenas o fato de se conhecerem que chamava a atenção, mas a crença de que elas travavam relações mágicas durante encontros secretos, os chamados Sabás. Desta forma, "a adoração do Diabo em forma de animal, as orgias sexuais e os infanticídios entraram, de modo duradouro, no estereótipo do Sabá" 24 .

Embora Michelet tenha se oposto, pelo menos em parte, à imagem que poder-se-ia ter de tais encontros ao afirmar que "as mulheres convergiam à festa atraídas pelo banquete, pela dança, pela iluminação, pela alegria, pela fascinação de toda a festa; de maneira alguma pelo prazer carnal" ${ }^{25}$, acredita-se haver certa dificuldade em desvincular as duas citadas atividades. $O$ imaginário, por inúmeras vezes, propôs figuras de mulheres nuas dançando em uma loucura lasciva, "as pessoas entregavam-se aos piores desregramentos sexuais" ${ }^{, 6}$, além da imagem clássica do acreditado hábito de beijar o traseiro do Diabo. Nestes aspectos, observamos a concordância de Julio Baroja, que vem acrescentar a noção da existência de uma divisão na sociedade (inquisidores e bruxas), separando tanto interesses quanto atividades cotidianas e, conseqüentemente, levando a julgamentos de valor e atividades persecutórias.

Além das relações travadas com o Diabo durante os Sabás, também havia a crença de que as bruxas possuíam a capacidade de transmutação: "vestiam-se de forma rebuscada mas tinham patas de gato ou cascos eqüinos"27. Essa metamorfose, inteira ou parcial, executada pelas bruxas tinha, em grande maioria, caráter zoomorfo. Tal mostra de proximidade, ou ainda, afinidade com animais, leva-nos a outro terreno: a existência de 'bestas' diretamente ligadas à bruxaria. A noção de diferença entre animais 'perfeitos', ou seja, aqueles criados por Deus, bem acabados e lapidados; e 'imperfeitos', entenda-se aqueles também de criação divina, porém não terminados, e por isso de aspecto repugnante, como cobras, sapos ou ratos, além também de gatos e corvos, trazia à mentalidade - já impregnada de idéias e noções 'bruxescas' - preconceitos

\footnotetext{
${ }^{23}$ DELUMEAU, Op. Cit., p. 378

${ }^{24}$ GINZBURG, Carl. História noturna. São Paulo: Cia das Letras, 1991, p. 89

${ }_{25}^{25}$ MICHELET, Jules. La Bruja, Barcelona: Ed. Labor, 1984, p. 146

${ }^{26}$ DELUMEAU, Op. Cit., p. 351

${ }^{27}$ GINZBURG, Op. Cit., p. 119
} 
contra tais animais, já que a associação destes com a imagem da bruxa era muito facilmente feita. A figura destes bichos foi, muito provavelmente, aos poucos, sendo deturpada para a de pequenos demônios, ou mesmo que tais animais poderiam ser os próprios demônios. Essas idéias levaram a Inquisição a procurar um pedaço de carne, uma 'teta' no corpo da mulher, "na qual o familiar [animal que executava serviços mágicos para a bruxa] podia sugar o sangue dela como forma de alimentação" 28 .

A demonização da figura feminina deu-se não apenas no âmbito popular, como até agora se havia dito, mas em toda uma eclesia de casta mais elevada. A Igreja "foi convidada a confundir (...) sexualidade e pecado, Eva e Satã". ${ }^{29}$ Parecia instaurar-se uma luta maniqueísta. Entretanto, segundo o Malleus, a figura divina não apareceria de modo ativo: "três elementos se fazem necessários à prática da bruxaria: o Diabo, a bruxa e a permissão de Deus" ${ }^{30}$. Analisando tal afirmação, parece-nos que a imagem demoníaca aparecia com mais freqüência que a de Deus, já que este possuía representação de um Ser invisível e onipresente, enquanto o Diabo manifestava-se claramente entre as pessoas comuns, principalmente entre as bruxas, induzindo-as e tentando-as. Contudo, Keith Thomas lançou uma idéia um tanto diferente: a de que a noção do Diabo vinha exatamente como que para reforçar a existência de Deus. Mais além, também observar-se-á "possível que a bruxa, às vezes, visse a si mesma como instrumento de Deus" ${ }^{\prime 3}$, como no caso de Joan D'Arc, levada à fogueira em 1431. Apesar de casos assim, a regra explicitava uma luta entre forças do bem e as do mal, tanto que, ainda no Malleus, defendia-se a crença de que certas pessoas estavam protegidas contra qualquer poder que uma bruxa viesse a lhes aplicar, pessoas estas que faziam uso dos poderes e virtudes da Igreja e que foram abençoados por Deus. Esta era, portanto, a inegável força protetora e benéfica, a qual as praticantes de bruxaria ofendiam de modo mais imperdoável do que se podia imaginar: "tão hediondos são os crimes das bruxas que chegam a superar, em perversidade, os pecados e a queda dos anjos maus"32.

O enorme medo do Diabo é facilmente explicado pois, além de ser o antagonista de Deus, há também uma explicação advinda de seu próprio nome: "Diabolus, de Dia, ou seja, dois e de Bolus, ou seja partes: pois o Diabo mata duas partes: o corpo e a alma." ${ }^{, 33}$ No entanto, o que levaria a um temor intenso das mulheres? Já nos referimos sobre os casos de isolamento e/ou a ausência de amparo, porém, verifica-se que o próprio corpo feminino, o próprio fato de se

\footnotetext{
${ }^{28}$ THOMAS, Op. Cit., p. 362

${ }^{29}$ DELUMEAU, Op. Cit., p. 322

${ }^{30}$ KRAMER e SPRENGER, Op. Cit., p. 156

${ }^{31}$ THOMAS, Op. Cit., p. 414

${ }^{32}$ KRAMER e SPRENGER, Op. Cit., p. 184

${ }^{33}$ Idem, p. 93
} 
'ser mulher' era um importante elemento explicativo. Delumeau cita um poema do monge Bernard de Morlas, de Cluny, de extrema violência contra a figura da mulher, incitando a misoginia. O poema data do século XII, porém seu conteúdo se manteve através do tempo, sendo ainda mais exaltado durante a 'Era da Inquisição'. Anne Barstow, por sua vez, confirmará tal visão ao dizer que "algumas das imagens mais básicas e negativas do imaginário das feiticeiras eram assim tiradas da anatomia feminina" ${ }^{34}$. O próprio Martelo das Feiticeiras trará um motivo, ou ainda, uma explicação um tanto quanto interessante sobre o 'podre' existente na mulher:

\begin{abstract}
"A razão natural está em que a mulher é mais carnal do que o homem, o que se evidencia pelas suas muitas abominações carnais. E convém observar que houve uma falha na formação da primeira mulher, por ter sido ela criada a partir de uma costela recurva, ou seja, uma costela do peito, cuja curvatura é, por assim dizer, contrária à retidāo do homem. E como, em virtude dessa falha, a mulher é animal imperfeito, sempre decepciona e mente" 35
\end{abstract}

Como se tais problemas não bastassem, outros fatores contribuíam diretamente para a visão negativa do sexo feminino. "Tidas em toda parte como sexualmente insaciáveis e fracas de caráter, as mulheres eram consideradas vulneráveis às seduções do Demônio" ${ }^{36}$.

Neste contexto, toda uma gama de questões de âmbito sexual veio à tona. Como excelente exemplo temos as noções de existência de Íncubos e Súcubos. Os primeiros, do sexo masculino, tiveram seu nome vindo do Latim incubare, ou seja, 'se chocar com', ou ainda, literalmente incubar. Os segundos, do sexo feminino, têm seu nome literal como 'aquele que vem de baixo', porém, o significado dado a succuba é o de prostituta. No entanto, ambos os tipos de demônios - acreditava-se - possuíam o poder de adentrar nos sonhos das pessoas e com elas manterem relações sexuais. Pode-se observar, no Malleus, a preferência de tais figuras por atuarem em dias cristãos sagrados pois, além de ofenderem ainda mais a Deus, a danação das almas dos atingidos seria ainda maior, pelo fato de estarem cometendo sacrilégio. Porém, tais noções nada mais eram que uma espécie de fuga, uma explicação para acontecimentos não muito bem vistos aos olhos de uma pessoa, ou ainda, de uma sociedade conservadora: "sonhos sexuais e poluções noturnas podiam ser aliviados pela reflexão de que um íncubo ou um súcubo deviam ter entrado em ação $" 37$.

${ }^{34}$ BARSTOW, Op. Cit., p. 169

${ }^{35}$ KRAMER e SPRENGER, Op. Cit., p. 116

${ }^{36}$ BARSTOW, Op. Cit., p. 32

${ }^{37}$ THOMAS, Op. Cit., 387 
Tal caráter sexual é retratado de inúmeras formas, porém a essência permanece sempre a mesma: "acreditava-se que as mulheres eram mais próximas do Diabo e elas eram, portanto, mais sujeitas à tentação e mais escravizáveis, dada a sua natureza física, que os homens." ${ }^{38}$ A noção de envolvimento sexual com demônios, ou com o próprio Satã, criou, ou melhor, exacerbou o medo em relação a certas mulheres. Porém, desta vez não havia apenas o medo de uma colheita ser destruída, o terror tornou-se mais profundo, na medida em que atingia fortemente o âmbito do sexo. No Malleus é encontrado um trecho sobre este assunto, cujo conteúdo vale a pena ser reproduzido:

\begin{abstract}
"Existem, conforme se lê na Bula Papal, sete métodos pelos quais elas [as mulheres] contaminam, através da bruxaria, o ato venéreo e a concepção; primeiro: fomentando no pensamento dos homens a paixão desregrada; segundo: obstruindo a sua força geradora; terceiro: removendo-lhes o membro que serve ao ato; quarto: transmutando-os em bestas pela sua magia; quinto: destruindo a força geradora das mulheres; sexto: provocando o aborto; sétimo: oferecendo, em sacrifício, crianças aos demônios, além de outros animais e frutos da terra, com que causam enormes males" 39 .
\end{abstract}

Imaginar que as bruxas possuíam o poder de inutilizar o órgão masculino através da impotência; ou ainda, através de ilusionismo ou encantamento, fazer parecer, dar a impressão de que o órgão masculino foi arrancado do corpo, com certeza teve uma enorme repercussão nas mentes da época. As mulheres passaram a ser vistas como perigosas, havia inclusive um "medo extremo de que a relação sexual durante a menstruação matasse o homem. ${ }^{40}$ Nota-se nestes exemplos, portanto, uma exacerbação, uma elevação da importância da sexualidade. Isto provavelmente deu-se de modo tão severo que, adicionado à profunda misoginia já existente, culminou em uma das linhas do Martelo das Feiticeiras: "que de todos os criminosos do mundo são as bruxas os que merecem a mais severa punição" ${ }^{41}$. Delumeau, em poucas palavras, tentou resumir aquilo que, provavelmente, foi uma das causas da subsequente explosão de violência para com as bruxas: "pode-se legitimamente

\footnotetext{
${ }^{38}$ ROPER, Op. Cit., p. 190

${ }^{39}$ KRAMER e SPRENGER, Op. Cit., p. 122

${ }^{40}$ BARSTOW, Op. Cit., p. 163

${ }^{41}$ KRAMER e SPRENGER, Op. Cit., p. 174
} 
presumir, (...) que uma libido mais do que nunca reprimida transformou-se neles [inquisidores] em agressividade" 42 .

Tem-se aí, portanto, o Tribunal da Inquisição. Nele, questões de justiça que anteriormente possuíam apenas caráter eclesiástico, tornaram-se então questões jurídicas. Nesse contexto, fortalece-se o papel do Juiz, cuja função era a de indagar a veracidade e as circunstâncias de um fato - apesar de constar que as respostas desejadas eram sugeridas durante o interrogatório. Ainda que o Tribunal tivesse como princípio ir contra os hereges e Satã, vale aqui salientar que tal Tribunal, apesar de sempre estar relacionado à Igreja, por vezes esta va acima desta, na medida em que as autoridades seculares, além de aprovarem a Inquisição, apoiavam-na. "A Inquisição (...) parecia, portanto, uma instituição conquistadora que deveria marchar por si mesma, penetrar em um todo e esse todo invadir" 43 .

$\mathrm{O}$ que se deve aqui observar são os dois diferentes lugares de onde as acusações provinham. Provavelmente, a maior parte delas era advinda do povo, das clássicas 'brigas entre vizinhos', que logo em seguida exigiam que os religiosos processassem os acusados. "As [acusações] que vêm da população local mencionam apenas malefícios; ao contrário, as formuladas pelo juízes giraram cada vez mais em torno do pacto e da marca diabólica, do sabá e das liturgias demoníacas" ${ }^{44}$. O que se verifica, e é de grande interesse, é a mudança que ocorre no discurso desde quando o acusado está sendo visto apenas por um igual do povo, até quando está nas mãos de um juiz do Tribunal.

O objetivo primordial dos interrogatórios era o de obter uma confissão para aquilo de que se era acusado, ou melhor, com a consequiente e constante transformação e distorção das perguntas, podia-se facilmente passar de uma acusação banal para um crime seríssimo, como o de bruxaria e o de envolvimento sexual com o Diabo. Porém, "confissões espontâneas só eram aceitas pelos juízes se fossem libeladas e traduzidas na linguagem que lhes era familiar, a da demonologia" ${ }^{45}$; neste sentido, "a linguagem da bruxaria as forçava [bruxas] a apresentarem o Diabo como seu sedutor e a última causa de sua queda/paixão" ${ }^{46}$.

O Malleus traz, passo a passo, os estágios de um processo inquisitório, porém apenas aqueles considerados como mais importantes serão aqui abordados. Em um primeiro momento, a bruxa acusada passava por um processo frente a testemunhas, no qual os questionamentos tinham o objetivo de entender a causa e a natureza da acusação; neste mesmo momento, dúvidas

\footnotetext{
${ }^{42}$ DELUMEAU, Op. Cit., p. 320

${ }^{43}$ MICHELET, Op. Cit., p. 166

${ }^{44}$ DELUMEAU, Op. Cit., p. 374

${ }^{45}$ Idem, p. 381

${ }^{46}$ ROPER, Op. Cit., p. 206
} 
eram levantadas com a intenção de confundir, favorecendo o aparecimento de respostas contraditórias. Podia-se acreditar que, neste momento, "a maior alegria do Diabo (...) era propor ao juiz, através da boca da feiticeira, argumentos embaraçosos, insidiosas perguntas." ${ }^{47}$ Não satisfeitos, os juizes poderiam levar a bruxa para um local de detenção e tortura. Neste, seus pêlos eram raspados para que não ocultassem qualquer símbolo ou marca do Demônio e seu corpo era vasculhado na procura destes sinais. "Em uma sociedade onde a nudez era rara, ele [torturador] conhecia seu [da bruxa] corpo melhor do que qualquer outra pessoa" ${ }^{48}$.

Após esta fase, testes, cujo conjunto era denominado 'o juízo de Deus', eram efetuados. Tratava-se de provas que poderiam evidenciar a identidade de uma bruxa, como partes do corpo que não sangravam ao serem picadas por uma agulha, ou o conhecido 'teste da água', no qual a mulher acusada, para não ser considerada bruxa, ao ser lançada na água deveria afundar. Por fim, caso até este momento nada atestasse a existência de uma bruxa na pessoa em questão, passava-se à tortura propriamente dita - "O acusado deve ser torturado de tal forma que saia saudável para ser liberado ou para ser executado" ${ }^{49}$ - durante a qual, na maior parte dos casos, uma confissão era retirada e, por conseqüência, tinha-se a permissão de pronunciar a sentença definitiva.

A pena máxima para os casos de bruxaria confirmada era a execução pública na fogueira, cujo uso teve seu auge durante o século XVI. Outras sentenças utilizadas eram a forca e o colar de estrangulamento, porém, "ao se queimar o corpo de uma bruxa, evita-se assim que o sangue dela se torne hereditário (...) o que o enforcamento não faz" ${ }^{50}$. O livro de Delumeau traz tabelas sobre o número das condenações e o que se observa é uma quantidade significativa de processos e execuções nas regiôes católicas em relação às protestantes. Fica "em destaque um período de severidade máxima nos últimos anos do século XVI, quando se acalmam as guerras religiosas" 51

\footnotetext{
${ }^{47}$ MICHELET, Op. Cit., p. 169

${ }^{48}$ ROPER, Op. Cit., p. 205

${ }^{49}$ EYMERICH, Op. Cit., p. 211

${ }^{50}$ THOMAS, Op. Cit., p. 376

${ }^{51}$ DELUMEAU, Op. Cit., p. 361
} 


\section{Em vias de conclusão:}

Pode-se notar que, em um dado momento da História, as mulheres, tornaram-se alvo de denúncias da chamada bruxaria. "A idéia de vôos em vassouras ou forcados, a noção de um pacto com o Diabo selado por relações sexuais, o abandono sexual à dança nos sabás das bruxas, tudo parecia sugerir que a bruxaria estava relacionada com a culpa sexual e a atração entre homens e mulheres." ${ }^{25}$ Inúmeros aspectos permeiam o estudo dos processos da Inquisição e da bruxaria propriamente dita, o que acaba por tornar o assunto demasiado extenso. Portanto, tentou-se aqui fazer um apanhado geral das circunstâncias e da problematização moral e sexual da feminilidade. Pode-se dizer que "o intenso conteúdo sexual das perseguições por feitiçaria no século XVI corresponde ao crescimento bem documentado das leis de restrição da conduta sexual." ${ }^{53}$ Desta forma, somos levados a pensar no papel desempenhado pelo desejo dos próprios inquisidores e torturadores ao se confrontarem com o corpo suspeito da bruxa. Porém, isso é uma outra história que deveria, em algum momento, ser tratada com o cuidado merecido. No presente trabalho, foi abordado um acreditado e 'praticamente concreto' imaginário, cuja importância se fez sentir na medida em que "Satã era (...) o senhor do prazer" 54 , e sua - acreditada - intensa relação com as mulheres tornou-as alvo de extremo temor. Conclui-se, portanto, que tudo acabava por convergir para esses bodes expiatórios pois, afinal, "como não temer um ser que nunca é tão perigoso como quando sorri? A caverna sexual tornou-se a fossa viscosa do inferno" 55 .

\section{Bibliografia Consultada:}

BAROJA, Julio Caro. As Bruxas e o seu Mundo. Lisboa: Editorial Vega, 1971 BARSTOW, Anne Llewellyn. Chacina de Feiticeiras: uma revisão histórica da caça às bruxas na Europa. Rio de Janeiro: Ed. José Olympio, 1995 DELUMEAU, Jean. História do medo no ocidente: 1300-1800. São Paulo: Cia das Letras, 2001

GINZBURG, Carl. História Noturna: decifrando o sabá. São Paulo: Cia das Letras, 1991 . Mitos, emblemas e sinais. São Paulo: Cia das Letras, 1989

MICHELET, Jules. La Bruja. Barcelona: Ed. Labor, 1984 ROPER, Lyndal. Oedipus \& the Devil: witchcraft, sexuality and religion in

\footnotetext{
${ }^{52}$ ROPER, Op. Cit., p. 202

${ }^{53}$ BARSTOW, Op. Cit., p. 159

${ }^{54}$ KRAMER SPRENGER, Op. Cit., p. 15

${ }^{55}$ DELUMEAU, Op. Cit., p. 314
} 
early modern Europe. Londres: Ed. Routledge, 1994

THOMAS, Keith. Religião e o declínio da magia: crenças populares na Inglaterra, séculos XVI e XVII. São Paulo: Cia das Letras, 1991

\section{Fontes:}

EYMERICH, Nicolau. Directorium Inquisitorium [1376]. Brasília: Ed. Rosa dos Tempos, EDUNB, 1993

KRAMER Heinrich e SPRENGER James. Malleus Maleficarum: O Martelo das Feiticeiras [1486]. Rio de Janeiro: Ed. Rosa dos Tempos, 2000 